Abnormal skeletal development has occurred in chick embryos exposed to this agent and transplacentally acquired tetracycline has produced appreciable inhibition of fetal growth in rats. ${ }^{3}$ Chromosomal aberrations and a reduction in the mitotic index have been found on adding tetracycline to human lymphocyte cultures ${ }^{4}$ and in premature infants transient inhibition of skeletal growth has been observed during the short-term administration of tetracycline. ${ }^{3}$ It is several years since Carter and Wilson ${ }^{2}$ reported a case of bilateral congenital deformity of the hands (absence of ring and little fingers and allied metacarpals, with webbing of the index and middle fingers) in an infant whose mother had received tetracycline early in pregnancy but their cautionary advice against the prenatal use of tetracycline seems as pertinent as ever.

Although no definite conclusions can be reached regarding the role of tetracycline in this case, the incomplete fibrous ankylosis and bone changes are of interest given the tendency for this agent to localise in developing skeletal tissues. ${ }^{3}$ Moreover, although arthrogryposis has been attributed to prolonged intrauterine pressure, possibly this disorder may originate early in embryonic life before such a factor can operate. ${ }^{5}$

Hence it is advisable that women who are trying to conceive or having unprotected intercourse should either not receive prolonged tetracycline treatment for acne, or should use contraception while taking it, and that the medication should be stopped as soon as possible in an unplanned pregnancy. ${ }^{1}$

${ }^{1}$ Greene, G R, New England fournal of Medicine, 1976, 295, 512.

${ }^{2}$ Carter, M P, and Wilson, F, British Medical fournal, 1962, 2, 407.

${ }^{3}$ Cohlan, S Q, Bevelander, G, and Tiamsic, American fournal of Diseases of Children, 1963, 105, 453.

+Westland, M M, fournal of the American Medical Women's Association, $1967,22,719$.

${ }^{5}$ Warkany, J, and Kirkpatrick, J A, jr, in Textbook of Pediatrics, by Nelson, Gaughan, and McKay, p 1349. Philadelphia, Saunders, 1969.

(Aceepted 6 May 1977)

St Catherine's Hospital, Birkenhead, Merseyside L42 0LQ

R CORCORAN, MB, MRCOG, consultant obstetrician and gynaecologist JULIET M CASTLES, MB, CHB, senior house officer

\section{Long-term colchicine prophylaxis in familial Mediterranean fever}

Small doses of colchicine will prevent the attacks in most patients with familial Mediterranean fever (FMF, recurrent polyserositis). ${ }^{1}$ Nevertheless, long-term administration of colchicine raises the problems of chromosomal abnormalities ${ }^{2}$ and azoospermia ${ }^{3}$ which may occur and are of great importance in children and in adults wanting to have children. The present report summarises the results of treatment in 47 patients, 24 of whom have received colchicine for between one and four years.

\section{Patients}

The 47 patients with typical FMF who are included in this study had extensive routine laboratory investigations before they were started on colchicine $(0.5 \mathrm{mg}$ per $25 \mathrm{~kg}$ body weight divided in one to three daily doses) and at six-month intervals thereafter. Both men and women were advised to stop treatment three months before trying to achieve pregnancy; 26 were male and 21 female, the youngest being 9 years old and the oldest 60 . Before colchicine treatment, the attacks had appeared at intervals of less than one month in 21 patients, every two to three months in 20 , and at intervals longer than three months in six. Only one patient had renal amyloidosis proved by kidney biopsy.

Of the patients, 35 received colchicine in a daily dose of $1.0 \mathrm{mg}$, seven $0.5-0.75 \mathrm{mg}$, and five $1.5 \mathrm{mg}$ colchicine and $1.0 \mathrm{~g}$ aspirin daily. Twenty-four patients $(51 \%)$ received treatment for one year or more, while the total period of observation amounted to 60 patient-years. Complete remission of symptoms was achieved in 46 cases, the remaining patient continuing to have mild attacks. Colchicine had no effect on the acute attack, and one or two, usually milder, attacks appeared in some cases during the first weeks of treatment. Transient failure due to underdosage (four cases) and to lack of compliance (eight cases) was not infrequent. Patients who voluntarily discontinued treatment after prolonged absence of symptoms had recurrence of attacks sometimes as early as two to three days after stopping the tablets. A 17-year-old girl told us that she could induce attacks by stopping treatment for 48 hours whenever she wished.

The only adverse reactions to colchicine were mild diarrhoea and abdominal pain, which occurred in three patients and disappeared after readjustment of the dose. Periodic examination of the urine, blood count, and blood chemistry showed no abnormal changes. Enhancement of growth was seen in all patients below the age of 16 who were treated for six months or more (see table). Three pregnancies occurred in the wives of three men and one in a woman while under treatment. The latter underwent transabdominal amniocentesis during the 15 th week of gestation. She had received $1.0 \mathrm{mg}$ colchicine daily for 46 months before conception and during the first trimester of her pregnancy. Chromosomal analysis of cultured amniotic fluid cells showed no aneuploidy or chromosomal breakage. Colchicine was discontinued and she remained symptom free during the rest of the pregnancy, but had a severe attack five days after the delivery. Her child, as well as the children of the three men, was born healthy with no congenital anomalies. Two additional men and one woman discontinued medication before the onset of pregnancies which have not yet come to term.

Effect of colchicine on growth in five young patients treated for six months or more

\begin{tabular}{c|c|c|c|c|c}
\hline $\begin{array}{c}\text { Case } \\
\text { No }\end{array}$ & Age & Sex & $\begin{array}{c}\text { Duration of } \\
\text { treatment } \\
\text { (months) }\end{array}$ & $\begin{array}{c}\text { Initial } \\
\text { height } \\
\text { (cm) }\end{array}$ & $\begin{array}{c}\text { Growth } \\
\text { (cm) }\end{array}$ \\
\hline 1 & 16 & $\mathrm{M}$ & 12 & 139 & 12 \\
2 & 16 & $\mathrm{M}$ & 12 & 165 & 7 \\
3 & 14 & $\mathrm{~F}$ & 12 & 133 & 7 \\
4 & 11 & $\mathrm{M}$ & 6 & 127 & 5 \\
5 & 12 & $\mathrm{~F}$ & 6 & 135 & 7 \\
\hline
\end{tabular}

\section{Comment}

Not only did colchicine improve FMF in our patients, but there were also no alarming untoward adverse effects. Furthermore, stunted growth, a neglected sign in FMF children, was dramatically corrected in five cases. These results are in keeping with studies of long-term colchicine prophylaxis in gouty arthritis, ${ }^{4}$ while the results of cytogenetic studies were no different from those in control subjects (to be published). Our observations also indicate no effect of long-term colchicine treatment on fertility, teratogenicity, or chromosomal integrity.

The effect of colchicine on amyloidosis is still unknown. The incidence of amyloidosis in FMF is controversial and figures ranging between nil and $26 \%$ have been reported. Probably amyloidosis is more frequent in Sephardic Jews with a heavy genetic load and much rarer in sporadic cases, in Ashkenazi Jews, and in Armenians. Zemer et al reported reduction in albuminuria in six patients with FMF receiving colchicine for six to twelve months. ${ }^{5}$ Since amyloidosis leads to death in an average of seven years, the effect of colchicine on its incidence is of crucial importance. The possibility of its prevention is, however, a strong argument in favour of starting long-term colchicine treatment in patients with FMF.

${ }^{1}$ British Medical fournal, 1975, 2, 60.

${ }^{2}$ Ferreira, N R, Lancet, 1968, 2, 1304.

${ }^{3}$ Merlin, H E, Fertility and Sterility, 1972, 23, 180.

4 Yu, T F, and Gutman, A B, Annals of Internal Medicine, 1961, 55, 179.

${ }^{5}$ Zemer, D, et al, New England fournal of Medicine, 1976, 244, 170.

(Accepted 11 May 1977)

Department of Medicine A, Hadassah University Hospital, Jerusalem, Israel

$M$ LEVY, MD, senior lecturer

M ELIAKIM, MD, professor; established investigator, Chief Scientist's Bureau, Ministry of Health 